\title{
Correction to: Highly selective and sensitive electrochemical determination of cysteine based on complexation with gold nanoparticle-modified copper-based metal organic frameworks
}

\author{
Ashraf M. Mahmoud ${ }^{1} \cdot$ Saad A. Alkahtani ${ }^{2} \cdot$ Mohamed M. El-Wekil $^{3}$ \\ Received: 1 February 2022 / Accepted: 1 February 2022 / Published online: 5 February 2022 \\ c) Springer-Verlag GmbH Germany, part of Springer Nature 2022
}

\section{Correction to: Analytical and Bioanalytical Chemistry} https://doi.org/10.1007/s00216-021-03852-0

The authors would like to call the reader's attention to the fact that, unfortunately, there was an error in the funding information of this manuscript. The original article has been corrected; please find the correct information below.

Funding The authors are thankful to the Deanship of Scientific Research at Najran University for funding this work under the General Research Funding Program grant code [NU-MRC-10-361].

Publisher's note Springer Nature remains neutral with regard to jurisdictional claims in published maps and institutional affiliations.

The original article can be found online at https://doi.org/10.1007/ s00216-021-03852-0.

Mohamed M. El-Wekil

mohamed.elwakeel@pharm.aun.edu.eg

1 Department of Pharmaceutical Chemistry,

College of Pharmacy, Najran University, Najran,

Kingdom of Saudi Arabia

2 Department of Clinical Pharmacy, College of Pharmacy, Najran University, Najran, Kingdom of Saudi Arabia

3 Department of Pharmaceutical Analytical Chemistry, Faculty of Pharmacy, Assiut University, Asyut, Egypt 